\title{
The discrediting strategy in the pre-election political discourse (based on the example of debates between Donald Trump and Joe Biden)
}

\author{
Diana Abdurakhmanova*and Ekaterina Redkozubova \\ Southern Federal University, 344000, Rostov-on-Don, Russia
}

\begin{abstract}
Speech manipulation in the pre-election discourse aims to influence the audience in order to increase the number of the electorate and present their political activities in a more favorable way. This article is devoted to the study of ways to achieve this goal using strategies of selfpresentation and discrediting. It is known that the political struggle for power at the stage of debate is carried out mainly through a strategy of discrediting. The task of belittling the opponent's status comes to the fore. Such activity involves a set of certain tactics that help to implement it: from the most common tactics of accusation and ridicule to less frequent tactics of exaggeration and unproven undermining of authority. This analysis demonstrates the variety of tactics used by Donald Trump and Joe Biden in the 2020 political debate as part of a discrediting strategy. The result of the study showed that politicians resort more to tactics of open speech influence, which takes place in offhand speech. In addition, the efficiency of the strategy of discrediting in political discourse was revealed.
\end{abstract}

\section{Introduction}

The development of modern linguistics makes researchers understand the need to move from descriptive forms of research to other types of scientific investigations making it possible to consider the perspectives of scientific studies in close relationship with the communicative and pragmatic characteristics of interlocutor. In other words, in the course of scientific research linguists admit the necessity of paying attention not only to the phenomenon of human language as such, but to objectification of the personal characteristics of the subject as well. Within this approachhuman speech may be viewed as an important part of the subject's communicative interaction with the objective reality around speakers. The possibility of considering linguistic issues in the system of personality-oriented priorities allows the researcher to take into account the mental reactions of the subject in his speech acts;it also provides an opportunity to systematize the objects of the world, including their forms, properties and characteristics in a new way.

In the process of political communication, the addressant sets the goal of his speech behavior to influence the addressee and change his presuppositions, assessments and ideas in order to update his communicative intention and achieve effective interaction. Such an

* Corresponding author: dianazalimovna@mail.ru 
impact becomes possible only through the identification of the linguistic tools used by the speaker - certain communication strategies and tactics -and the realization of their pragmalinguistic potential. Of particular note, Charles Sanders Peirce and Charles W. Morris defined linguistic pragmatic as the science the subject of which is a ratio of a speaker to thesigns used by him. The problem of speech acts and speech formation is also described in the linguistic concepts of K. L. Buhler, B. Y. Gorodetsky, G. G. Matveeva, N. I. Formanovskaya and other authors in which the speech act is determined as a way for a person to achieve a certain goal. That it is carried out purposeful speech act in accordance with the principles and rules of verbal behavior adopted in a given society. For pragmalinguistics, a significant factor is the interpretation and specification of the mechanism of human behavior in order to provide a speech impact on one's interlocutor. Therefore, in pragmalinguistic studies, the person as the subject of speech activity is put in the first place. In the process of speech communication, the reproducer of the speech act does not act as a developing, idealized personality with all its inherent psychological, ethical, ideological and social features, but as a person who reveals several of his social functions and psychological features, depending on the specific conditions of communication. That is why for our study we chose two people with an individual set of socio-psychological characteristics, with a certain life experience and behavior patterns (including speech patterns), Donald Trump and Joe Biden, in order to consider their behavior in the pre-election political discourse.

There is a point of view that speech is mainly not the transmission of information, but a means of affecting and controlling people's activities. The transmission of information is clearly present in the speech message, but it is not an end in itself. Each person is exposed to speech influence at the moment of communication. The concepts of speech communication and speech influence are among the main concepts of pragmalinguistics. In this regard, it is possible to define the speech influence in a broad and narrow sense. In a broad sense, any speech communication can be considered a speech influence since it is purposeful. In a narrow sensespeechinfluence is understood as the control of human behavior with the help of speech. Through speech influence,one can encourage a person to start or finish an activity, expand their awareness, change their emotional state and life attitudes. In various areas of mass communications, which includes the field of politics, language acts as a powerful tool for gaining public support. It is no secret that in political communication, oratory has always been the most important tool for achieving certain political goals. It is generally accepted that good politicians resort to the help of those who are excellent at oratory and are able to successfully apply it in practice. Such factors as education, family, society, and economic status are undoubtedly reflected in the speech of a politician, but they are often leveled as they master excellent oratorical skills. In this article, we will be interested in the linguistic means used by Donald Trump and Joe Biden to influence the recipient.

\section{Literature Review and Methodology}

In linguistics, several methods of studying speech influencehave been developed. It depends on the researcher what methods and scientific paradigm he will resort to. The choice of methodology also determines the form of the studied speech (oral or written) and the style of the text. It can be defined the following " stages" of linguistic influence:

-phonological

-nominative

-semantic

-syntactic-logical

-contextual and semantic 
-formal-symbolic.

From our perspective, the linguistic means of influence should be described in a similar way, although much more fully and with the use of cognitive and semiotic tools. A specific direction of suggestive linguistics developed somewhat separately. Since the 1990s, there has been a tendency to consider speech influence in oral and written communication. In the latter case, the speech effect was found in the journalistic and newspaper style.The basic research materials were usually advertising texts, the content of leaflets, slogans and others. There are certain characteristics which are typical of oral and small genres of written texts. The main of them are the abundance of stereotypes, briefness, the impact of the extra linguistic factors, definite psychological and social roles of the interlocutors. The properties mentioned above are recognized as beneficial for studies within the framework of theories of speech influence.

The study of speech influence originates in rhetoric - the science of methods of persuasion, various forms of mainly linguistic influence on the audience.In the context of pragmalinguistics, auxiliary means of speech influence are studiedsuch as speech strategies and tactics, the use of certain pictorial and expressive means of language and others. Under the speech strategy, E. Teneva [1] understands a structured set of speech actions that are carried outto achieve the speaker's communicative goal. G. Manolov [2] gives the following definition of speech strategy: a situationally conditioned set of systematic actions of the interlocutor with a specific goal, intentions in relation to his communication partner, which are implemented through a specific tactic or a set of tactics.In turn, speech tactics includes specific communicative actions used within the chosen communication strategy.

Summarizing the essential characteristics of speech influence, we can give the following definition. Speech influence is an arbitrary and involuntary transfer of information by a subject to a recipient(a recipient can mean not only one person, but also a whole society or an association of people) that takes place in oral and written forms of human communication. Itis carried outwith the help of linguistic and non-linguistic symbolic means. In addition, it is determined by certain factors, the most essential of which are addressant's conscious or unconscious purposes and goals of communication. The goals may be objective, communicative or informative.Besides, such points as presuppositions and a specific sign situationare taken into account as well. The speech effect also has a downside. It is the "communicative impact" that this or that message has on the recipient.

If we consider the interaction of the interlocutors (that is the subject and the object), then we can distinguish direct and indirect speech influence. Direct speech influence is carried out as a result of a meaningful choice of the so-called communicative-speech forms. As we have mentioned earlier, this can result in a change in behavior, prompting a response or taking an action.

Indirect speech influence is carried out implicitly and also brings about modifications in the recipient's behavior, but remains invisible to him. Here we can find the use of hidden mechanisms of speech influence. These include psychological techniques, suggestive techniques, implicatures, indirect speech acts and others. As some authors point out, direct and indirect speech influenceismaterialized by affecting cognitive and emotional states and can be argumentation and manipulationdepending on the purpose of the impact. Let us consider manipulation in more detail. By means of manipulative mechanisms of speech influence, information is transmitted by "intrusion" into the consciousness of the recipient the message of the framed idea. Speech manipulation can be carried out at the level of both interpersonal communication and mass communication, namely the pre-election political discourse.

According to our point of view, the pre-election discourse is a certain area of communication, which has a close connection with the time and place of the election campaign. In addition, electoral discourse serves a specific social sphere, namely political 
elections. It should be mentioned that the pre-election discourse belongs to the journalistic style. As we know, the main goal of this style is to provide a deep effective emotional and psychological impact on society and its opinion, to convince the reader or listener to understand the question inherent in the speaker. Thus, it is an official public speech, which maintains in its essence a certain emotional mood and contains calls and motivations for action.

Thus, looking at the picture presented by various scientists, we can say that the preelection discourse is the so-called reflection of the socio-political life of the country. Such a discourse will certainly reveal the burning and pressing problems of society, reflecting the expectations of the people. In this case, politicians resort to using speech influence as the most effective way to convince the audienceand thereby achieve the goal of expanding their electorate.

Consequently, the goal of our work is to study the basic techniques and tactics of manipulating consciousness in the pre-election political discourse using the example of Donald Trump and Joe Biden.

The main research methods in our work were the methods of content analysis, comparative analysis, discourse analysis, continuous sampling and the contextual method.

The theoretical basis of the research was formed by publications of modern Russian and foreign linguists, raising the issues of speech influence, language strategies and tactics, namely E.Teneva [1], G. Manolov [2], A. Lyulina [3], R.Ivanova [4], Y. Mala [5], T. Tameryan [6], E. Polyakevich [7], M. Sirivlja [8], I. Essina [9], N. Sklyarova, L. Khacheresova [10,11].

Given the nature of this study, its results may be of practical value for specialists in the humanities who deal with speech influence in their work. The considered tactics and strategies in the pre-election discourse, clearly used by political leaders in their speech, can be successfully demonstrated as examples in the educational process. A characteristic set of certain tactics and strategies can be recommended for identifying speech influence act in other discourses.

\section{Results and Discussion}

Currently political discourse is the most promising area of linguistic science since political life plays a key role in the life of modern society. Politics isquite a peculiarfield of human life and it contains a peculiar set of speech actions. The power struggle is the main driving force of politics. This can be expressed in the evaluativeness of statements, the aggressiveness of expressions, which presupposes defending one's point of view [12].Undoubtedly, we can observe a clash of opposing opinions and interests in political discourse and this determines the use of a whole range of speech strategies.

Moreover, the goal setting of political discourse requires from an addressant such an arrangement of speech behavior that would ensure the attraction of people to its side and inspire the correctness of the given actions and assessments. In this sphere of communication the subjects are divided into "friends" and "aliens and as a rule, speech behaviorobeys a certain strategy, the general content of which is reduced either to affirmation, praise or to criticism debunking the views and actions of politicians representing a particular party or movement.

It is important to note that researchers have not come to a unified approach and a strict classification of tactics and strategies, however, the strategy of discrediting is one of the most important and leading in the space of pre-election discourse, along with the strategy of self-presentation.

It is customary to separate two strategies of manipulation: a strategy of discrediting and a strategy of self-presentation. The strategy of self-presentation is understood as the 
imposition on the object of speech influence of the impression that the subject produces. There are two techniques for managing an impression. The first technique is "basking in reflected glory". Its essence lies in the use of someone else's success for the purpose of their own elevation. The researchers called the second technique in one word "blasting". The essence of this technique is to deliberately exaggerate the shortcomings of something or someone to improve their own status in the eyes of others.

According to the resultsof our investigation, the strategy of discrediting being put into political practice is used in order to lower the status of the opponent. The politicians who use this strategy are trying to undermine the people's confidence in their adversary, his actions, words and prestige [13]. In this regard, we reckon it appropriate to consider it. Primary it should be recalled that there are various tactics and techniques within the framework of this strategy. They can be direct or indirect.Foremost we will dwell on the use of such tactics in the implementation of a discrediting strategy.

\subsection{The tactic of accusation}

The tactic of the accusation consists in exposing political rivals to the public, embezzling guilt, presenting the situation and the opponent in a negative way. The speaker tries to find and reveal the negative traits and intentions of his opponent. In order for this tactic to take place in discourse, they usually resort to lexical means with a negative evaluative meaning. Such accusations are often unsubstantiated and unfounded.

Consider Donald Trump's example in the 2020 election debate: "While we are standing here, why is it just out of curiosity, the mayor of Moscow's wife gave your son three and a half million dollars? What did he do to deserve it? 'Quite clearly, Trump accuses Biden and his family of corruption while not providing evidence. He applies irony (just out of curiosity) in the second interrogative sentence, accompanying it with a rhetorical question. As we know, linguists classify a rhetorical question as a figure of persuasion. Namely, the interrogative construction in the rhetorical function contains an emotional statement. A rhetorical question presupposes the presence of an obvious and unambiguous answer, so D. Trump emphasizes the significance and truth of his thought with its help. In addition, the form of the rhetorical question helps to highlight the most significant information from the flow of speech and focus the audience's attention on it.

Further, Trump repeated the accusation more than once in response to which he received Biden's reaction that this was not true [14]. None of them provided evidence and the situation forced Biden to use offensive tactics. He used the lexeme "clown" in his speech in relation to Trump saying that it was impossible for him to prove anything [14].Such a reaction is highly predictable in an unprepared speech in response to the tactics of the accusation. It involves insult, hurt someone, humiliation accompanied by the explication of the emotional component.

Some definite communicative steps are used to implement this tactic, they are expressed in a negative characteristic of the opponent, and theiroffensive nature is obvious. The tactic is of low use due to the existing "moral and ethical" (as well as legal) restrictions on its use. Negatively evaluative vocabulary with a negative connotative component is designed to discredit the adversary, as much as possible shortening the path from premises to the necessary conclusions that the audience supposedly should make (and actually accept). Such methods of struggle against the background of the general aggressiveness of the preelection communication, such "attacks" do not shock the audience.

There is also the so-called tactic of impersonal accusation. It differs somewhat from the tactic of accusation in that both tactics have different ways of expressing the object of the accusation. It is important to bear in mind that the implementation of the accusation tactic is 
associated with the explicit nature of the object while the implementation of the impersonal accusation tactic is associated with the implicit nature of the object.

It is beneficial for a politician to focus the listener's attention on the object without naming the subject of the action, since this enhances the pragmatic effect of opposing "our" and "alien" worlds, that is the listener's consciousness is fixed on negative circumstances that he encounters everywhere.

During the debate, Donald Trump says that before he took office, the previous presidential administration including the vice-president did not work as hard Donald Trump himself did in three years. He does not directly name Vice President Biden but alludes to him. This is immediately understandable because the overall purpose of the debate is to belittle one's opponent, that is, the context helps to reveal the tactics of impersonal accusation.

Tactics can be combined. For instance, in the speech fragment "At the Democrat National Convention, Joe Biden and his party repeatedly assailed America as a land of racial, economic and social injustice, so tonight, I ask you a simple question: How can the Democratic Party ask to lead our country when it spent so much time tearing down our country?" the tactic of accusation are combined with the dialogue tactic. Using the questions in his monologue, the author, as it were, addresses each person directly, forcing them to think about the correctness of the decision made regarding the candidates. Politicians quite often use such techniques in organizing their speech, because this allows creating an atmosphere of trust and a certain closeness between the author and the listener. Using the lexical units "assail", "injustice", "tear down", the politician tries to demonstrate Joe Biden's hostility towards his country.

In turn, Joe Biden draws the public's attention to the fact that Donald Trump is doing his best to divide the country due to the diversity of nationalities and religions. In continuation, the Democratic candidate resorts to a contrasting strategy of self-presentation, aimed at strengthening his own position and pointing out his positive aspects. After Joe Biden resorted to the tactics of blaming his opponent, he emphasizes the opposite of the Democratic Party which is aimed precisely at uniting the country. Moreover, the candidate repeats several times in his speech the idea of the equality of the population of the country, the need to treat each resident with respect, regardless of his origin, religion, etc.

\subsection{The tactic of exposure or unmasking}

From the speaker's point of view, the tactic of exposure or unmaskingis aimed at revealing the true face of his opponent exposing in the eyes of voters.

Further Trump appealed to namely this tactic. The debate host asked Donald Trump why Americans should trust him to solve racial problems and not Joe Biden. The former US president did not fail to recall that in 1994 Joe Biden wrote a crime bill in which he called African Americans super predators [14].In this case, Trump cites a specific fact. This fact does not raise any doubts in Donald Trump that he wants to convince others. Therefore, in his quote "In the bill African-Americans are super predators in his opinion and they've never forgotten it. They've never forgotten it"deliberately uses lexical repetition which makes this expression not a dry statement of facts but an expressively colored narrative. Throughout the phrase, there are techniques that help to implement the unmasking tactics. For example, the use of homogeneous predicates in combination with polysindeton (said, gave, and want, and demand), inversions (taking the time circumstance to the beginning of the sentence), give the expression expressiveness and emotionality. Biden himself positions himself as a politician close to the people, as evidenced by lexical units unusual for political discourse (hugs, even kisses); against this background, his actions (writing such a law) are perceived as a betrayal of the people's interests. 


\subsection{The tactic of ridicule}

Another tactic implemented within the framework of the strategy of discrediting is the tactic of ridicule. Its implementation is possible with the help of stylistic techniques. The use of such expressive means as grotesque, irony, sarcasm, prank, pun, hyperbole, jokeand others can be reallyfunctioning if there is a need to harm the opponent's image, addatticism and beautiful speech accents without going beyond the bounds of decency and official business style of storytelling.

We believe that it is possible to draw a parallel between the lexemes "mock", "ridicule", "humiliate"and "insult". Their semantics contains a common component of going beyond what is permitted when performing speech actions. Ridicule refers to a variety of offensive expressions that cause a sharp decrease in the status of the object of the utterance through derision of his personal qualities. This speech tactic is not regulated by the principles of communicative tolerance and the system of ethical norms.

In English-language discourse, ridicule is often associated with contempt and is mimicked in the form of twisted lips. One can also differentiate ridicule as more evil and less derogatory. In the first case, the speaker has a goal to harm the object of the utterance, while the latter is the addressant's desire to have fun, and the ridicule is more mocking than evil.

The objects of ridicule in American political discourse can become both political competitors of the subject of the utterance and various social, political and economic groups. For instance, in the following statement Donald Trump makes fun of political refugees: "They're all met by the lawyers. They say, say the following phrase: I am very afraid for my life. I'm afraid for my life. I look at the guy. He looks like he just got out of the ring, he's the heavyweight champion of the world. He's afraid for his life? It's a big, fat con job, folks. It's a big, fat con job" [15]. Donald Trump using the lexical repetition of the adjective "afraid" deliberately belittles the meaning of this word, indicating the insincerity of people wishing to obtain refugee status in the United States. Moreover, the president makes fun of the appearance of one of the expats, comparing him to the heavyweight wrestlers and uses the invective and negative epithets "big" and "fat" combined with the idiom "a con job", enhancing the characterization of the object of the utterance as an impartial swindler, trying to get into the country illegally. Emotionally expressive tone statements allows D. Trump to appeal not to the reason and logic of his voters, but to feelings, i.e. not so much convincing them of the need to strengthen anti-emigration legislation, how much to entertain and deform existing in the mind recipients, the image of refugees as people fleeing social and political injustice in other countries.

The tactic of ridicule can be not only verbalized but also visualized. Therefore, Donald Trump inhis microblog posted a video where his competitor Joe Biden, the former vice president of the United States, is being harassed by himself with the help of an editing technique. Trump has accompanied his post with the mocking signature WELCOME BACK JOE, aggressively ridiculing the return of a rival to big politics, as well as an election scandal involving accusations of inappropriate behavior by several Biden's women.

With a stand-alone discursive element "as always" following homogeneous "on the job" and "presidential", Biden, in turn, ridicules tactlessness and unprofessionalism of Trump who is engaged not in presidential affairs but in discrediting opponent on social networks.

Returning to the 2020 debate, there is an example of verbalized ridicule. In this quote from Donald Trump: "These same policies led to crippling power outages in California just last week .... How can Joe Biden claim to be an ally of the light when his own party can't even keep the lights on?"the word "light" is used twice in different meanings [15]. One is abstract the other is material. The contrast between Biden's claim to be a "light guide" and 
his failure to solve the problem of power outages makes the presidential contender comic. Another emotional accent is the epithet "crippling" which amplifies the effect of Biden's non-constructive governance. Besides, the author resorts to the tactics of dialogization addressing the audience, offering them another reason to think about the correctness of their choice.

\subsection{The "labeling" tactic}

It is noteworthy that this is a common tactic of manipulation in general in the media. People in the mainstream media try to anticipate our perception of the event covered by labeling positively or negatively. Some of the positives are "stability," "strong presidential leadership," "strong defense," and "healthy economy." Some common negative labels include "leftist guerrillas," "Islamic terrorists," "conspiracy theories," "gangster groups in the city center" and "civil unrest".

Beyond that, labels are attached using precedent-setting phenomena. Returning to the speech of D. Trump in the pre-election debates, we can observe an allusion towards his rival Joe Biden. D. Trump metaphorically attributes to him the image of a Trojan horse, thereby using the "labeling" tactic.

In the quote cited "Biden is a Trojan horse for socialism ... Then how is he ever going to stand up for you?" [15]. Trump argues that Biden is too weak to resist radical forces. The speaker sets the vector for the development of the audience's thought, completing this statement with another interrogative sentence. It is important to stress that the Trojan horse metaphor is not original. It was also used in relation to F. Roosevelt, B. Clinton, B. Obama and even D. Trump himself. Trump has used this metaphor since his first campaign in 2016.

Thus, this label is an unreasonable, subjective, emotional characteristic with the aim of evoking negative associations and leading the listener to the conclusions the speaker needs.

\subsection{The "polarization" tactic}

We dare to assume that since the goal of the struggle for power is to convinceand influence the addressee to maintain the ideology of social values and the rules of the game of the ruling political party, the whole process is directly related to deliberately opposing "us" and "them". This opposition has an impact on the behavior of politicians and, in particular, on their speech behavior. Therefore, in the speech of politicians, we can clearly trace the divergence of our views and those of our opponents to "different poles."

Throughout the fragment of the monologue during the debatesD. Trump refers to one and the same discrediting tactic of polarization aimed at opposing one political force to another. Exclusively positive actions are inherent for one side, for the other - completely opposite, negative ones. Trump is adept at using arguments for his team and demonstrating his merits in areas where his opponent made a mistake. As a rule, such opposition is accompanied by an indication of the scale of Biden's negative influence on America: "We have spent the last four years reversing the damage Joe Biden inflicted over the last 47 years". The lexical units "inflict" and"damage" explicate the harm done to the country by Biden. Trump's actions are in positive contrast to those of a political adversary.

\subsection{The tactic of reproach}

The next tactic that we would like to consider in the context of political discourse is the tactic of reproach. The tactic of reproach is based on the expression of displeasure, 
disapproval of someone. In our case, such statements are expressed in relation to their political opponent.

Consider the following snippet taken from the 2020 election debate between Trump and Biden. "We can't lock ourselves up in a basement like Joe does. He has the ability to lock himself up. He's obviously made a lot of money someplace and he can live in a basement. People can't do that. By the way I as the president couldn't do that'[14]. The context allows us to understand that despite the pandemic situation, Trump had to meet with people and he could not "lock himself at home" as Joe Biden did. In the given example, the reproach is expressed implicitly. A pronoun "he" is deliberately used instead of a proper name to add a touch of dismissiveness.

Based on the foregoing, it can be understood that the reproach emphasizes the speaker's negative attitude towards the current situationas a result of which a positive opinion about Trump's activities is formed.

It seems important to us to emphasize that in this way Donald Trump is actively implementing a strategy of self-presentation, which helps him build a positive image of himself as the President of the United States. The speaker tells the audience that he is not afraid of the current situation, but rather goes out into society, organizes meetings and works for the benefit of his people. In the context of D. Trump's speech, such information stands out since he presents his political opponents in an unfavorable way. Obviously, this is a careful course in terms of manipulation.

\subsection{The tactic of ascertaining the incompetence of the enemy}

This tactic is used when you need to point out the opponent's shortcomings directly in professional activities. In this case, all possible gaps in the understanding of the political matter are "revealed". Such tactics most often directed against opponents, competing parties and preceding governments. In most cases, opponents are called openly an assessment is explicitly given to them and their actions.

In the process of the pre-election debate, D. Trump uttered the phrase "But he had eight years he was Vice President. He did nothing except build cages to keep children in". This is a direct indication of the incorrect implementation of the immigration reform expressed to D. Baden when he served as vice president.D. Trump openly declares the inability to carry out the reform in the form in which it is necessary and thereby casts doubt on the competence discrediting the opponent.

This tactic is used infrequently. It is implemented in political discourseespecially rarely since it is rather difficult to reveal the incompetence of politicians due to their high level of professionalism in general.

\subsection{The tactic of hyperbolization}

This tactic assumes a false interpretation of the statement or action made by the opponent. This interpretation is based not on the violation of logical connections but on exaggeration of the meaning of what was said. It is necessary to distinguish between hyperbole as exaggeration and amplification. When amplified, the speaker only emotionally evaluates the reported fact and when exaggerated, he gives this fact a certain "quantitative measure." Such a measure presupposes either a comparison of facts or indicates clearly exaggerated, implausible dimensions of the object that go beyond the reality of the action or utterance.

Considering this tactic as part of the strategy of discrediting the enemy in political discourse, we can note that it has a fairly frequent nature of its implementation.

In the 2020 debate, Joe Biden says that D. Trump has done nothing to prevent coronavirus infection. Quoting: "And again, I go back to this. He had nothing, he did 
virtually nothing. And then he gets out of the hospital and he talks about, "Oh, don't worry. It's all going to be over soon". Come on. There's not another serious scientist in the world who thinks it's going to be over soon". In addition, here we can trace a quote from Trump, reproduced by Biden himself. The latter deliberately exaggerates Donald Trump's words with the lexemes "not another scientist", "in the world" in order to expose the opponent in an unfavorable way.

\subsection{The tactic of unproven undermining the authority of the enemy}

D. Trump uses the tactic of unproven undermining the authority in the following statement: "But I'll tell you, Joe, you could never have done the job that we did. You don't have it in your blood". The politician issues a negative value judgment, questioning Biden's ability to work. The expression "to have something in blood" implies a lack of qualities needed by a leader. This statement is groundless without any reasoning.

In a statement about the education of our opponent, we can observe the use of reverse direct tactics, namely, evidence-based undermining of authority: "You graduated either the lowest or almost the lowest in your class. Don't ever use the word smart with me. There's nothing smart about you, Joe. 47 years you've done nothing". With the phrase "there's nothing smart about you," the politician indicates low mental abilitiesbased on the fact that Biden did not do well in college. Trump brings up the age of his opponent again, saying that Joe has forgotten the name of his college. Evidence-based tactics are presented here using arguments - statements.

Further D. Trump uses the tactic of exposing the opponent using provocative information. An example is the accusatory statements directed against the son of Joe Biden: "He was thrown out dishonourably discharged. For cocaine use. And he didn't have a job until you became vice president". The speaker emphasizes the high immorality of the soldier's behavior using emotionally colored vocabulary "thrown out", "dishonourably", mentions the fact of his son's use of cocaine. Trump accuses Biden of abusing his power since his son is hired not according to merit but thanks to his father's connections.

Thus, the tactic of unproven undermining the authority of the enemyis expressed mainly explicitly and takes place most often in unprepared speech. Moreover, both opponents resorted to this tactic already at the end of the debate. The reason for it is the nature of this tactic, which has a quite high level of emotionality.

\section{Conclusions}

The analysis showed that politicians operate with open and straightforward statements and try to create a negative image of their opponent with the help of negative evaluative judgments or even insults. Tactics inherent in argumentative discourse, for example, dominate Donald Trump's speech. However, direct invention tactics with a greater emotional coloring are most popularin debates. This is due to the fact that Trump's speech is premeditated, while his speech in the debate is offhand. Debates require an instant reaction from the participants, candidates do not have the proper time to select implicit means of manipulation, they often neglect the observance of the norms of decency and speech etiquette, therefore the narrative language is simplified and the emphasis is on the transparency of speech tactics and the expressiveness of communicative units.

Thus, a discrediting strategy is a natural form of building an election or campaign speech of any politician, as well as an effective line of conduct in debates. By giving a negative assessment to their opponent, Trump and Biden indirectly increase their reputation. Having built their speeches only on the strategy of self-presentation, they would not have been able to achieve the same effect since all attempts to create a positive image of 
their party are more obvious and cause less confidence among voters. It can be argued that the strategy of discrediting implies the strategy of self-presentation.

\section{References}

1. Ekaterina Teneva, Science. Research. Practice: a collection of selected articles based on the materials of the International Scientific Conference, 148-151 (2020). doi: 10.37539/SRP291.2020.81.15.007

2. George Manolov, Media Linguistics 5 (4), 545-556 (2018). doi.org/10.21638/spbu22.2018.412

3. Anna Lyulina, Modern Scientist 1-2, 70-72 (2017).

4. Rimma Ivanova, Journal of Siberian Federal University. Series: Humanities \& Social Sciences 9, 2082-2091 (2016). doi: 10.17516/1997-1370-2016-9-9-2082-2091

5. Yulia Mala, Philological sciences 1(22), 26-28 (2016).

6. Tatiana Tameryan, Social and Cultural Transformations in the Context of Modern Globalism, (2019) doi: 10.15405/epsbs.2019.12.04.406

7. Elena Polyakevich, Currrent Research of Young Scientists in the Field of Humanities, 129-133(2017)

8. Madina Sirivlja, International Journal of Experimental Education 12, 49-51 (2013).

9. Irina Essina, Russian Linguistic Bulletin 3 (23), 9-13 (2020). doi: 10.18454/RULB.2020.23.3.28

10. Natalia Sklyarova, Lyubov Khacheresova, Tomsk State University Journal 418, 44-52 (2017). doi: 10.17223/15617793/418/6

11. Natalia Sklyarova, Lyubov Khacheresova, Vestnik Tomskogo Gosudarstvennogo Universiteta. Filologiya 68, 85-108 (2020). doi: 10.17223/19986645/68/5

12. LiliyaPolyakova, YuliaYuzhakova, Tatyana Zalavina, Natalya Dyorina, Revista Amazonia Investiga 9(33), 27-36 (2020) doi:10.34069/AI/2020.33.09.3

13. Valeria Petrenko, Anna Potapova, Procedia. Social and Behavioral Sciences 154, $482-$ 485 (2014)

14. Donald Trump \& Joe Biden $1^{\text {st }}$ Presidential Debate Transcript 2020, https://www.rev.com/blog/transcripts/donal d-trump-joe-biden-1 st-presidential-debatetranscript-2020

15. Donald Trump \& Joe Biden Final Presidential Debate Transcript 2020, https://www.re v.com/blog/transcripts/ donald-trump-joe-biden-final-presidential-debate-transcript2020 